\title{
International experiences with priority setting in healthcare
}

\author{
Bert Gordijn · Henk ten Have
}

Published online: 12 June 2013

(C) Springer Science+Business Media Dordrecht 2013

For several reasons the problems of priority setting in healthcare are most likely not going to be solved anytime soon. First, in many countries demographic changes are leading to an increased average age of the population. Since most financial resources for healthcare are used in the final years of life, healthcare expenditures tend to rise with changing demographics. This trend is already reflected in the growing healthcare budgets of western countries. In addition, the discrepancy between available means and costs is worsening since a smaller percentage of the inhabitants have to pay a bigger bill for health care. Second, supply and demand in healthcare seem to be interconnected by positive feedback loops. Supply has grown as medical R\&D has truly globalized in the last few decades. As a result novel medical technologies and pharmaceutical products are being developed at an ever accelerating pace. In addition, the interest in medical enhancement products demonstrates that the demand for healthcare products and services is almost unbounded. This may elicit a huge further scaling-up of the medical market leading to soaring costs. Third, the problem of identifying and justifying fair distributions of benefits and burdens in healthcare is exceedingly intricate. Theoretically, it is complex as there are several different theories of justice (for example, egalitarianism, utilitarianism and libertarianism) that seem to be applicable and are being applied to the problem of choices in healthcare by foremost scholars leading to very different distributive results. In addition, the problem of

\footnotetext{
B. Gordijn $(\bowtie)$

Dublin, Ireland

e-mail: bert.gordijn@dcu.ie
}

H. t. Have

Pittsburgh, USA advancing fair distributions is difficult from a practical point of view as well as there are different levels of distribution (macro, meso and micro), each with different agents and stakeholders. Fourth, prioritization is not a dossier that is popular amongst politicians. Quite to the contrary, engagement with it seems to be widely perceived as a political career risk. So the national policy makers, who would be the obvious agents to deal with the problem in a transparent and democratically controlled manner, are usually not actively pursuing solutions as effectively as would be desirable. As none of the above mentioned factors is likely to disappear or substantially change, prioritization in healthcare will remain problematic.

Against this backdrop it is interesting to learn more about ways of trying to tackle the problem in different countries. Hence the first three papers of this issue review the experiences with prioritization in Germany, Israel and Scandinavia-Denmark, Norway and Sweden. Fuat Oduncu (2013) starts with a review of the German experience with priority setting. Surprisingly, in Germany prioritization has only been debated in depth in the last couple of years. The current discussion was triggered by a combination of significantly increased healthcare cost and a decreased birth rate putting mounting pressure on healthcare. In the German healthcare system solidarity based Statutory Health Insurance covers $90 \%$ of the population whilst the remaining $10 \%$ are privately insured. In order to select necessary medical services the Central Ethics Commission of the Federal Association of Physicians in Germany has advanced criteria such as medical need, evidence based benefit, fitness for purpose and cost-benefit-effectiveness. Oduncu (2013) calls for further public debate preferring transparent criteria over implicit priority setting and rationing.

Next Frida Simonstein (2013) focuses on the Israeli experience with priority setting, which-in contrast to 
Germany_goes further back to the 1990s. Since 1995, when the National Health Insurance (NHI) law came into force, Israel has had a system of universal health care coverage funded by a system of progressive taxation. Two years later a formal priority setting procedure was put into place in order to take decisions on the inclusion of new medical services into the existing package of benefits covered by the NHI. A multidisciplinary Public Committee was to advance recommendations about new additions to the benefits package, but the Minister of Health would take all final decisions. Understandably, as the work of the Public Committee developed over the years, a critical public debate about this explicit process of priority setting ensued. After a change of the composition of the Public Committee, forced through by the Minister of Finance, the Israeli Medical Association established a non-official prioritization committee. This shadow body has gained quite some influence mainly through a significant media presence. In the last few years concerns have been raised about life-saving medications not included in the NHI benefits package. These medications are only covered by newly created voluntary health insurance packages. It is feared that further privatization of Israel's health care system might undermine ideas of equity and state responsibility for public health. Simonstein (2013) equally stresses the importance of transparency in the further debates and decision making processes around priority setting.

Finally, Bjørn Hofmann (2013) reviews the experiences with priority setting in health care in three Scandinavian countries: Denmark, Norway and Sweden. All these countries have publically funded healthcare systems with universal coverage. The public debate in Scandinavia goes even further back than the Israeli discussions, which make them interesting case studies for other countries. After describing the individual experiences in Denmark, Norway and Sweden, and reviewing differences and similarities Hofmann stresses three developments in the Scandinavian priority setting experience: (1) from approaches dominated by experts towards participatory strategies, (2) from approaches essentially informed by principles towards advisory board led practice definition procedures, and (3) from closed modi operandi towards methods characterized by openness. In addition, he identifies five models of priority setting that have all been tried out in Scandinavia over the last twenty years analysing the pros and cons of each of these models. Hofmann (2013) claims a thorough discussion of the Scandinavian trends and models might be useful for other countries in order to further develop their own priority setting strategies. There is no question the same holds true for the experiences in Israel and Germany.

\section{References}

Bjørn Hofmann. 2013. Priority setting in health care: trends and models from Scandinavian experiences (this issue).

Fuat S. Oduncu. 2013. Priority-setting, rationing and cost-effectiveness in the German health care system (this issue).

Frida Simonstein. 2013. Priorities in the Israeli health care system (this issue). 